\title{
Exploração sexual da criança e do adolescente no Brasil
}

\author{
Grasiele Augusta Ferreira-Nascimento ${ }^{\star}$, Maria Aparecida-Alkimin ${ }^{\star *}$
}

* Doutora em Direito e Relações Sociais pela Universidade Católica de São Paulo. Professora do Centro Universitário Salesiano de São Paulo -U. E. de Lorena-, Brasil.

\section{Correo electrónico:}

direito@lo.unisal.br

** Doutora em Direito e Relações Sociais pela Universidade Católica de São Paulo. Professora do Centro Universitário Salesiano de São Paulo -U. E. de Lorena-, Brasil.

Correo electrónico:

maalkimin@terra.com.br

Recibido: 6 de agosto del 2012 Aprobado: 21 de abril del 2013

Cómo citar este artículo: Grasiele Augusta Ferreira-Nascimento \& Maria Aparecida-Alkimin. Exploração sexual da criança e do adolescente no Brasil. DIxI. Junio 2013. At. 79.

\section{Resumo}

A exploração sexual da criança e do adolescente como forma degradante de trabalho infanto-juvenil caracteriza umas das mais graves violações aos Direitos Humanos na atualidade. O objetivo do presente estudo, realizado através de levantamento bibliográfico nacional e internacional, é propor políticas, medidas e ações efetivas que busquem a prevenção e a erradicação da exploração sexual da criança e do adolescente garantindo o desenvolvimento e a formação física, psíquica, intelectual, moral e social sadia e equilibrada das crianças e dos adolescentes.

Trata-se de um trabalho de investigação científica concluído e desenvolvido através do Grupo de Pesquisa "Minorias, Discriminação e Efetividade de Direitos", do Programa do Mestrado em Direito do Centro Unisal de São Paulo (UE de Lorena) e apresentado no III Seminário Latino-americano de Direitos Humanos -Direitos Humanos, Multiculturalismo e Diversidade na América Latina, cuja investigação científica teve início no ano de 2011 e foi concluída no ano de 2012.

Palavras-chave: adolescente, criança, exploração sexual infantil, proteção integral.

\section{EXPLOTACIÓN SEXUAL DE NIÑOS Y ADOLESCENTES EN BRASIL}

\section{Resumen}

La explotación sexual de niños y adolescentes es una forma degradante de trabajo infanto-juvenil que caracteriza una de las más graves formas de violación de los derechos humanos en la actualidad. El objetivo del presente estudio, realizado mediante levantamiento bibliográfico nacional e internacional, es proponer políticas, medidas y acciones efectivas que busquen la prevención y erradicación de la explotación sexual de niños y adolescentes, garantizando un desarrollo y una formación física, psíquica, intelectual, moral y social sana y equilibrada en los niños y adolescentes.

Fue llevado a cabo por el grupo de investigación "Minorías, discriminación y eficacia de los derechos" del programa de maestría en derechos del Centro de Derecho de Unisal of Sao Paulo (EU Lorraine). Estuvo asociado con el III Seminario Latinoamericano en Derechos Humanos, Multiculturalismo y Diversidad en América Latina. La investigación comenzó en el 2011 y se terminó en el 2012.

Palabras clave: adolescente, niño, explotación sexual infantil, protección integral.

\section{Sexual Exploitation of Children and Adolescents in Brazil}

\section{Abstract}

Sexual exploitation of children and teenagers is a degrading form of child labor that is one of today's most serious human rights violations. The aim of this study, carried out by reviewing national and international literature, is to propose policies and actions to effectively prevent and eradicate sexual exploitation of children and teenagers, ensuring their healthy and balanced physical, psychological, intellectual, moral and social development.

It was completed by the "Minorities, Discrimination and Effectiveness" Research Group of the Masters Program on Rights at the Law Center at the Unisal of São Paulo (EU Lorraine). It was associated with the III Latin American Seminar on Human Rights, Multiculturalism and Diversity in Latin America. The research began in 2011 and was completed in 2012.

Keywords: adolescent, child, child sexual exploitation, comprehensive protection. 


\section{INTRODUÇÃO}

A criança e o adolescente recebem ampla proteção da legislação nacional e internacional.

No Brasil, o Estatuto da Criança e do Adolescente (ECA) considerou como "crianças" as pessoas com até 12 (doze) anos incompletos, e como "adolescentes" as pessoas com 12 (doze) a 18 (dezoito) anos incompletos.

Consideradas pessoas em desenvolvimento, as crianças e os adolescentes precisam de ampla proteção para que tenham um desenvolvimento físico normal, sem os prejuízos adquiridos do exercício de atividades degradantes e lesivas ao desenvolvimento físico, psíquico e moral, em especial no que se refere à exploração sexual da criança e do adolescente, que representa não só uma forma degradante de trabalho, como também uma grave violação aos Direitos Humanos dessas pessoas em desenvolvimento.

Contrariando a determinação legal, o Brasil ainda apresenta um elevado índice de trabalho infantil, presenciado não apenas zona urbana, mas também na rural. As crianças e os adolescentes brasileiros desenvolvem suas atividades nas carvoarias, no plantio e colheita de sisal, nas atividades de rua, no tráfico de drogas, no trabalho doméstico e no comércio "do sexo", por exemplo. Uma das piores formas de trabalho infantil e de violação aos Direitos Humanos, infelizmente, é a exploração sexual.

O nosso estudo objetiva abordar a prevenção e a erradicação da exploração sexual da criança e do adolescente, na busca da concretização da proteção integral, através do levantamento bibliográfico nacional e internacional sobre o tema.

\section{CRIANÇA E ADOLESCENTE E O PRINCÍPIO DA PROTEÇÃO INTEGRAL}

Criança, na acepção geral, é o indivíduo da espécie humana, menino ou menina, na fase da infância; na acepção jurídica e científica, a fase infantil (criança) vai do nascimento até a puberdade, ao passo que adolescente ou adolescência é a idade entre a puberdade e a idade adulta. Esta, por sua vez, refere-se à pessoa que atingiu a maturidade física e psíquica, o que significa, na acepção jurídica, que atingiu a maioridade civil; portanto, responde per si pelos atos da vida, pois há presunção de pleno discernimento e capacidade de autodeterminação na fase adulta.
A criança e o adolescente ${ }^{1}$ são pessoas em desenvolvimento físico, psíquico, intelectual, moral, social e espiritual, que se distinguem dos adultos em razão de a personalidade infanto-juvenil integrar um processo de desenvolvimento paulatino que somente na fase adulta culminará com a maturidade e o discernimento como forma de expressão da vontade livre e consciente.

Diante da condição de pessoas em peculiar condição de desenvolvimento, a criança e o adolescente devem usufruir de proteção especial ou cuidados peculiares através de normas específicas que lhes garantam proteção integral e que lhes permitam o desenvolvimento físico, psíquico, intelectual, social, moral e espiritual de forma sadia e em plenas condições de liberdade e dignidade. Portanto, a proteção especial à criança e ao adolescente tem razões de ordem biológica, psicológica, moral e cultural.

Bobbio, ao se reportar à Declaração dos Direitos da Criança (ONU, 1959), a qual instituiu a proteção especial à criança ao declarar que "a criança, por causa de sua imaturidade física e intelectual, necessita de uma proteção particular e de cuidados especiais", afirmou que "os direitos da criança são considerados como um ius singulare com relação a um ius commune;" dando ênfase, portanto, à espeficidade de direitos, cujos direitos da criança resultam "de um processo de especificação do genérico, no qual se realiza o respeito à máxima sum couidque tribuere". ${ }^{2}$

Com a evolução e o reconhecimento dos direitos humanos, novos direitos ou novas gerações de direitos foram emergindo em razão de condições peculiares em que se situam ou se colocam as pessoas, tais como o idoso, a criança e o adolescente, o consumidor etc., sendo que, para efetivação dos direitos humanos e garantias fundamentais, criou-se um sistema de especificação de direitos dentro dos direitos humanos reconhecidos a todo cidadão, como foi o caso da Convenção sobre os Direitos da Criança (ONU, 1989), o ECA (Lei 8.069/1990), o Estatuo do Idoso (Lei 741/2003), o Código de Defesa do Consumidor (Lei 8.078/1990).

Dentro desse sistema de especificação de direitos e de proteção à pessoa humana em condições peculiares

\footnotetext{
1 Convenção sobre Direitos da Criança. Art. 1: "considera-se como criança todo ser humano com menos de 18 anos de idade, a não ser que, em conformidade com a lei aplicável à criança, a maioridade seja alcançada antes." No Brasil, o art. 2 do ECA esclarece que: "considera-se criança, para os efeitos desta Lei, a pessoa até doze anos de idade incompletos, e adolescente aquela entre doze e dezoito anos de idade."

2 Ver Norberto Bobbio. A era dos Direitos. Tradução de Carlos Nelson Coutinho. Elsevier. (2004). p. 34
} 
e até mesmo em condições físicas, psicológicas e materiais inferiores, a ordem jurídica nacional e internacional houveram por bem criar um sistema normativo de proteção a essas pessoas em condições de vida ou posições na vida especiais.

Criança e Adolescente são titulares de direitos humanos consagrados pela Declaração Universal dos Direitos do Homem (oNU, 1948); entretanto, os direitos humanos consagrados às crianças recebem uma estruturação diferenciada em relação aos direitos humanos consagrados à população adulta, cuja estruturação diferenciada se manifesta através da especificação de direitos humanos, cuja especificação passou a integrar documentos internacionais que expressam um arcabouço de proteção especial e integral à criança e ao adolescente, ao considerar sua peculiar condição de pessoa em desenvolvimento e o reconhecimento da criança e do adolescente como sujeitos de direitos na órbita jurídica internacional.

As Constituições Modernas, inclusive a Constituição Brasileira de 1988 (CF) em consonância com as normas internacionais, reconheceu a criança e o adolescente como sujeitos de direitos e merecedores de ampla proteção do Estado, da sociedade e da família, com absoluta prioridade e de acordo com o princípio do melhor interesse da criança, impondo ao Estado o dever de assegurar, por meio de lei e por outros meios, os direitos humanos consagrados como direitos fundamentais e sociais pelos documentos internacionais e nacionais, como forma de permitir o pleno desenvolvimento da capacidade física, psíquica, moral, espiritual e social, bem como a salvaguarda da dignidade humana dessas pessoas em formação.

O Brasil, através do Art. 227 da CF/88, buscou estabelecer uma síntese da Convenção sobre os Direitos da Criança (onU, 1989) que exalta a concepção da criança como sujeito de direito, e a doutrina da proteção integral estabeleceu a prioridade absoluta em matéria de proteção (Art. 27, CDC), considerada o documento mais importante no âmbito internacional de proteção à criança em razão do elevado número de países ratificantes.

Na verdade, a Convenção sobre Direitos da Criança tem por fundamento a Declaração Universal dos Direitos da Criança (onU, 1959), que já mencionava a necessidade de proteção integral para o desenvolvimento integral da criança (físico, psíquico, moral, intelectual, social e espiritual) por parte do Estado, sociedade e da família, o que estabelece a universalidade e indivisibilidade dos direitos da criança e do adoles- cente, além de enfatizar a importância de se intensificar esforços nacionais e internacionais para a promoção e a defesa aos direitos da criança, inclusive em matéria de exploração sexual.

A proteção integral à criança e ao adolescente instituída pelo Art. 227 da CF foi regulamentada pelo ECA (Lei 8.069/1990), que consagrou, internamente, a doutrina da proteção integral e instituiu os direitos e garantias fundamentais e especiais da criança e do adolescente, ao demonstrar uma adesão à concepção moderna de direitos humanos interdependentes e indivisíveis.

Proteção integral, no sentido real, significa que um ser humano necessita de cuidado de outro ser humano e, no caso da criança e do adolescente, esse cuidado se estende à família, à sociedade e ao Estado, cujo cuidado também tem como fundamento uma relação de desigualdade de ordem física, psíquica, intelectual etc.

O termo proteção pressupõe um ser humano protegido e um ou mais seres humanos que o protegem, isto é, basicamente um ser humano que tem necessidade de outro ser humano. Obviamente, este segundo ser humano deve ser mais forte que o primeiro, pois deve ter capacidade para protegê-lo. ${ }^{3}$

Os direitos humanos e fundamentais da criança e do adolescente, dentro do sistema de proteção integral, gozam de prioridade absoluta, erigida à categoria de princípio constitucional (Art. $227 \mathrm{da} \mathrm{CF}$ ) e regulamentada pelo Art. $4^{\circ}$ do ECA que estabeleceu como prioridade absoluta em matéria de criança e adolescente a:

- primazia em receber proteção e socorro em qualquer circunstância;

- precedência no atendimento por serviço ou órgão público de qualquer poder;

- preferência na formulação e execução das políticas sociais públicas; e

- destinação privilegiada de recursos públicos às áreas relacionadas com a proteção da infância e da juventude.

Dessa forma, a proteção integral representa a defesa do melhor interesse da criança e a instituição da primazia ou prevalência dos direitos da criança e do adolescente em relação aos direitos das demais pessoas, além de impor ao Estado, à família e à sociedade o dever de proteção integral à criança e ao adolescente

\footnotetext{
3 Ver Pereira, T. da S. (2008). Tânia da Silva Pereira. Direito da criança e do adolescente - uma proposta interdisciplinar. CIDADE Renovar. (2008). P. 24. 
como forma de facilitar o pleno desenvolvimento físico, psíquico, intelectual, social, moral e espiritual.

\section{EXPLORAÇÃO SEXUAL DA CRIANÇA E DO ADOLESCENTE: UMA DAS PIORES FORMAS DE TRABALHO INFANTIL}

A Organização Internacional do Trabalho (oIT) reconheceu a exploração sexual como uma das piores formas de trabalho infantil.

De acordo com a Convenção 182 da OIT, entendese como exploração sexual "a utilização, o recrutamento ou a oferta de crianças para a prostituição, a produção de pornografia ou atuações pornográficas" (Art. $\left.3^{\circ}, b\right)$.

No Brasil, segundo os dados relatados por Guilherme Guimarães Feliciano, ${ }^{4}$

De um total de 3.328 denúncias de abuso e exploração sexual infanto-juvenil recebidas pela ABRAPIA entre fevereiro de 1997 e janeiro de 2003, 69\% (a maioria) referiam-se à prostituição infantil; $25 \%$ referiam-se a abusos pela Internet; $3 \%$ referiam-se a "turismo sexual"; $2 \%$ referiam-se à confecção e venda de material pornográfico com objeto infanto-juvenil; $1 \%$, enfim, referia-se ao tráfico de pessoas com finalidade sexual. São, em geral, situações que envolvem o jogo trabalho vs. remuneração (= consentimento da vítima + finalidade econômica) e que, por isso, subsomem-se bem às piores formas de trabalho infanto-juvenil elencadas no artigo $3^{\circ}$, «b», da Convenção 182. Daquele total, por fim, $11,50 \%$ referiam-se à exploração sexual infanto-juvenil sob o jugo familiar, sendo que, em $8,50 \%$ dos casos, o agente explorador era a própria mãe.

Como se vê, a noção de "exploração sexual" vai além do mero abuso ou da própria prostituição infanto-juvenil (o que explica os termos mais gerais - "prostituição, produção de pornografia ou atuações pornográficas"utilizados pelo Art. $3^{\circ}$, b, da Convenção 182 da OIT).

Muitas vezes de iniciativa dos próprios pais, que buscam a complementação da renda familiar através da prostituição dos filhos que, em grande maioria, são meninas entre 02 (dois) e 12 (doze) anos de idade.

O turismo sexual, por sua vez, também vem crescendo no país e ganhando repercussão internacional, não sendo raras as viagens de estrangeiros, sobretudo

4 Ver Guilherme Guimarães Feliciano. Violência sexual contra a criança e o adolescente no marco da precarização das relações de trabalho. Anais do I semidi e I seviles. Centro Universitário Salesiano de São Paulo. 2010. para a Amazônia e para diversas cidades litorâneas do norte e nordeste do país, com essa finalidade.

Entre os fatores que levam à realização do turismo sexual, encontram-se a falta de planejamento turístico, a exclusão social, o desemprego, a ausência de moradia, de escolaridade, dentre outros. Entre os problemas dessa prática, encontram-se a miséria, o alcoolismo, as drogas, as agressões físicas e o abuso sexual frequentes. ${ }^{5}$

Várias ações já foram implementadas para combater a exploração sexual infantil nas diversas regiões do Brasil, e envolveram vários setores, como o Ministério Público, a Polícia Rodoviária Federal, o Poder Judiciário, ONGS, CEDEDICAS, entre outros.

Na cidade de Ilhéus, no Estado da Bahia, por exemplo, o projeto "Sentinela", que faz parte da Secretaria de Ação Social e Trabalho do Município, oferece atendimento às crianças e adolescentes vítimas de violência sexual.

O projeto foi implementado em 2001 e, até o ano de 2010, acompanhou 508 casos, dos quais 48 (quarenta e oito) foram de exploração e 112 de abuso sexual. Dois dos casos acompanhados foram de tráfico de pessoas para fins de prostituição. De acordo com os dados do projeto, as meninas que partem para a prostituição ou para o turismo sexual normalmente foram abusadas pelos próprios familiares. A prostituição e o turismo sexual na região normalmente são realizados por intermédio de taxistas, proprietários de barracas de praia, donos de pousadas, bares e restaurantes.

Atualmente, a legislação brasileira responsabiliza penalmente os envolvidos na exploração sexual de crianças e de adolescentes. A própria $\mathrm{CF} / 1988$ estabeleceu como dever da família, da sociedade e do Estado "assegurar à criança e ao adolescente, com absoluta prioridade, o direito à vida, à saúde, à dignidade, ao respeito, à liberdade e à convivência familiar e comunitária, além de colocá-los a salvo de toda forma de negligência, discriminação, exploração, violência, crueldade e opressão" (Art. 227 da CF). Sem dúvida, uma das formas de violência e de crueldade é a exploração sexual.

O parágrafo $4^{\circ}$ do referido artigo dispõe que a "lei punirá severamente o abuso, a violência e a exploração sexual da criança e do adolescente".

O ECA considera a submissão de criança ou adolescente à prostituição ou à exploração sexual como prática delituosa, nos artigos abaixo transcritos.

5 Ver Tatiana Amaral Silva \& Marco Aurélio Ávila. Turismo sexual e exploração sexual infantil: uma análise da atuação do programa sentinela em Ilhéus. Revista de Turismo e Patrimônio Cultural. Disponível em: http:// www.pasosonline.org/Publicados/8110/PS0110_14.pdf. 06/10/2011. 
Art. 244-A - Submeter criança ou adolescente, como tais definidos no caput do Art. $2^{\circ}$ desta Lei, à prostituição ou à exploração sexual:

Pena: reclusão de quatro a dez anos, e multa.

$\$ 1^{\circ}$ - Incorrem nas mesmas penas o proprietário, o gerente ou o responsável pelo local em que se verifique a submissão da criança ou adolescente às práticas referidas no caput deste artigo.

$\$ 2^{\circ}$ - Constitui efeito obrigatório da condenação a cassação da licença de localização e de funcionamento do estabelecimento.

Art. 240 - Produzir ou dirigir representação teatral, televisiva ou película cinematográfica, utilizando-se de criança ou adolescente em cena de sexo explícito ou pornográfica:

Pena: reclusão de um a quatro anos, e multa.

Inclui quem contracena com a criança.

Art. 241 - Fotografar ou publicar cena de sexo explícito ou pornográfica envolvendo criança ou adolescente.

Pena: reclusão de um a quatro anos.

A responsabilidade também recairá sobre os pais dos menores explorados, os quais poderão responder pelas penalidades previstas nos Arts. 245, 246 e 247 do Código Penal, por exemplo, que compreendem, respectivamente, ao crime contra a assistência familiar, caracterizado pela entrega do filho menor de 18 (dezoito) anos à pessoa em cuja companhia saiba ou deva saber que o menor fica moral ou materialmente em perigo; crime de abandono material, caracterizado quando os pais deixarem de prover a instrução primária de filho em idade escolar; e crime contra a assistência familiar, na hipótese de os pais permitirem que o menor resida ou trabalhe em casa de prostituição. ${ }^{6}$

\section{Direitos Humanos e a EXPLORAÇÃO SEXUAL DA CRIANÇA E DO ADOLESCENTE}

É inegável que a exploração sexual da criança e do adolescente em qualquer nível ou modalidade constitui grave violação aos direitos humanos dessas pessoas em desenvolvimento físico, psíquico, social, intelectual, moral e espiritual.

Tal prática viola direitos inerentes à pessoa humana, tais como a integridade psicofísica e a liberdade in-

6 Ver Grasiele Augusta Ferreira Nascimento \& Maria Aparecida Alkimin. Exploração sexual: uma das piores formas de trabalho infantil. Anais do xx Congresso Nacional do CONPEDi/Ufes. 2011. At. 2455. dividual e sexual, cujos direitos se situam na órbita dos direitos naturais, daí o caráter inerente a toda pessoa humana; assim como viola os documentos internacionais e internos que representam a positivação da proteção integral e prioritária à criança e ao adolescente.

Sem dúvida, a exploração sexual viola a liberdade, autodeterminação, integridade psicofísica da criança e do adolescente, compromete seu desenvolvimento e amadurecimento sadio e equilibrado, retira-lhe o direito de ser e de se sentir criança, direito esse que transcende os direitos reconhecidos e protegidos pelo Estado, trata-se de um direito natural, integrante da essência de toda criança.

Os direitos humanos, direitos que nascem com o homem, com ele evoluem e somente com ele, homem, poderão perecer, foram reconhecidos e difundidos para toda a civilização por intermédio da Declaração Universal dos Direitos do Homem (onU, 1948).

A Declaração Universal dos Direitos do Homem consagrou a era dos direitos humanos e instituiu a concepção contemporânea dos direitos humanos através da sua internacionalização, o que conduziu à formação de uma cultura mundial de direitos humanos norteada por documento escrito sobre os direitos humanos, $\mathrm{e}$ que tem como traço marcante a universalidade e indivisibilidade ou interdependência ${ }^{7}$ desses direitos, e que também representa o instrumento que serve de fundamento basilar para o ordenamento jurídico no mundo inteiro, em especial, nos países ratificantes.

Os direitos humanos, segundo Bobbio, têm origem na filosofia jusnaturalista, portanto, inerentes à condição humana e independentes da vontade do Estado, ${ }^{8}$ foram reconhecidos em função única e exclusiva da pessoa humana, por conseguinte, o homem como ser racional, ou seja, aquele que detém a autodeterminação em suas ações no meio em que vive, constitui o fundamento único para promoção e proteção aos direitos humanos por parte do Estado-nação.

Pode-se afirmar que os direitos humanos têm como fim único a pessoa humana, ser dotado de razão e dignidade, e, nesse sentido, Kant, ao se referir à pessoa humana, afirmou que "de um modo geral, todo ser racional, existe como um fim em si mesmo, não simplesmente como meio do qual esta ou aquela vontade possa servir-se a seu talente". ${ }^{9}$

\footnotetext{
7 Ver id. Cit. 4.

8 Ver id. Cit. 4. P. 68.

9 Ver Fábio Konder Comparato. A afirmação histórica dos direitos humanos. 17a Ed. Saraiva. (2010). P. 33.
} 
A dignidade da pessoa humana, numa primeira fase, assumiu o caráter principiológico e naturalista, pois todos os homens nascem e morrem com algo que lhe é inerente: a dignidade humana, a qual corresponde a um atributo natural e indissociável do ser humano, de "caráter único e insubstituível de cada ser humano", ${ }^{10}$ e, após o reconhecimento e a positivação dos direitos humanos, portanto, com status de norma, o Estado avocou o dever de proteção e abstenção com relação a toda e qualquer forma de violação à dignidade da pessoa humana.

Como bem afirmou Bobbio, os direitos humanos, embora originários do direito natural, não foram reconhecidos e garantidos todos de uma só vez; na verdade, a evolução dos direitos humanos acompanhou a evolução da própria sociedade, e tornaram-se uma conquista da humanidade que, ao longo de sua história, ficou subjugo da vontade do Estatal.

Segundo Celso Lafer, ${ }^{11}$ mesmo após a positivação das declarações internacionais sobre direitos humanos, não ocorreu uma estabilização no elenco de direitos humanos contemplados nas Constituições e documentos internacionais, pois, à medida que a sociedade evolui $\mathrm{e}$ se transforma, novas necessidades e, consequentemente, novos direitos surgem, já que "é difícil atribuir uma dimensão permanente, não variável e absoluta a direitos que se revelaram historicamente relativos".

Dentro dessa evolução histórica da humanidade e do processo de construção e reconstrução dos direitos humanos, foram surgindo e sendo proclamados novos direitos e gerações de direitos, dentre eles foram proclamados os direitos humanos da criança como forma de proteção especial a essas pessoas com imaturidade física e psíquica e como meio de reconhecer a criança e $o$ adolescente como sujeitos de direitos.

$\mathrm{Na}$ verdade, ao tratarmos dos direitos humanos da criança, não queremos nos afastar da representação dos direitos humanos como uma unidade, ou seja, como um corpo único, que se constitui em unidade interdependente e indivisível, pois os direitos civis e políticos estão interligados com os direitos econômicos, sociais e culturais, um não se sustenta sem o outro, logo, ao haver violação, por exemplo, a direitos civis e políticos, haverá reflexos nos direitos sociais, econômicos e culturais, uma vez que os direitos humanos constituem uma unidade harmônica e indivisível.

10 Ver id. P. 42.

11 Ver Celso Lafer. A reconstrução dos direitos humanos: um diálogo com o pensamento de Hannah Arendt. P. 124. Companhia das Letras. (1988).
Tratam-se os direitos da criança, conforme apontado alhures, de ius singulares, caráter que adveio da Declaração dos Direitos da Criança (onU, 1959) e que enfatizou a necessidade de proteção particular e cuidados especiais à criança por causa da sua imaturidade física e intelectual, tendo a Convenção sobre os Direitos da Criança (ONU, 1989) primado pela garantia do desenvolvimento integral da criança, com absoluta prioridade, ao atribuir-lhe condição de sujeito de direito e considerar sua peculiar condição de pessoa em desenvolvimento físico, psíquico, social, moral e espiritual.

O Brasil, como país-membro ratificante da Convenção sobre os Direitos da Criança, introduziu na CF/1988 dispositivos que regulam os direitos humanos da criança, reconhecidos como direitos e garantias fundamentais e especiais da criança e do adolescente em razão da sua peculiar condição de ser humano em desenvolvimento, ao impor um sistema de garantias e proteção mais amplo e exigir a participação do Estado, da família e da sociedade (Art. 227 da CF/1988 e ECA, Lei 8.069/1990).

A exploração sexual contra a criança e o adolescente como instrumento de lucro, meio de garantia de subsistência ou como forma degradante de trabalho humano viola flagrantemente os direitos humanos da criança e do adolescente consagrados pela Convenção sobre os direitos da criança, bem como as normas internas de proteção que preveem expressamente a proteção contra a exploração e abuso sexual, bem como viola os direitos e garantias fundamentais reconhecidos e positivados no âmbito internacional e nacional, em especial, o direito "à liberdade, ao respeito e à dignidade" (Arts. 16-18 do ECA).

A Convenção sobre os Direitos da Criança, em seu Art. 19, impõe aos Estados-partes a adoção de medidas legislativas, administrativas, sociais e educacionais apropriadas para proteger a criança contra todas as formas de violência, inclusive, a proveniente de abuso sexual.

No âmbito internacional, ainda, e no que se refere à exploração econômica e sexual da criança, foi adotado em 25 de maio de 2000 o Protocolo Facultativo à Convenção dos Direitos da Criança, pela Resolução A/ REs/54/263 da Assembleia Geral, sob a denominação de Protocolo Facultativo sobre a Venda de Crianças, Prostituição e Pornografia Infantis, que impõe aos Estados -partes a obrigação de proibirem a venda de crianças, bem como a prostituição e pornografia infantis, bem como exige que os Estados-partes promovam a criminalização dessas condutas. Os direitos humanos da 
criança e do adolescente consagrados pelo ordenamento internacional e interno, tal como os direitos humanos consagrados pela DUDH, são absolutos, inalienáveis, indivisíveis e interdependentes, sendo certo que a violação através da exploração sexual da liberdade, da dignidade, do respeito, da saúde, reflete em violação aos demais direitos das crianças, enquanto sujeitos de direitos civis, políticos, sociais, econômicos e culturais.

A indivisibilidade e interdependência desses direitos indicam que a garantia, o respeito, a defesa e a promoção dos direitos humanos devem abranger todos de uma vez, pois a defesa da liberdade sexual e da dignidade da criança pressupõe a defesa e garantia da saúde, convivência familiar e social, cultural, o lazer etc., logo, é inconcebível a defesa individualizada dos direitos humanos da criança e do adolescente.

Pode-se afirmar que não basta o reconhecimento dos Direitos Humanos, há necessidade de sua efetivação e proteção para consolidar a dignidade da pessoa humana. Como bem afirmou Bobbio, não basta proclamar os Direitos Humanos, "o problema real que temos de enfrentar, contudo, é o das medidas imaginadas e imagináveis para a efetivação desses direitos". ${ }^{12}$

O combate à exploração sexual da criança e do adolescente é um problema de raízes profundas, cuja forma de violação a direitos da criança e adolescente constitui um sério problema na humanidade e que acompanha o desenvolvimento globalizado, tendo como origem o problema da exploração sexual a miséria, a fome, as condições de vida subumanas, enfim, a prostituição infanto-juvenil é fruto da pobreza, da exclusão e da desigualdade de oportunidades, cujos aliciadores muitas vezes são os próprios genitores ou parentes.

Para o estabelecimento de um sistema de proteção integral efetivo, eficaz e com resultados satisfatórios, não é possível a abstração do problema da exploração sexual do problema que assola a população mundial que é a fome, a pobreza, o desemprego etc.

\section{ConCRETIZaÇÃo DA PROTEÇÃo INTEGRAL EM MATÉRIA DE EXPLORAÇÃO SEXUAL: PREVENÇÃO E ERRADICAÇÃO}

Visando à concretização da proteção integral da criança e do adolescente, deve-se buscar o cumprimento e plena efetivação da prioridade absoluta e da

12 Ver id. Cit. 4. P. 37. prevalência do melhor interesse da criança e do adolescente, através da criação, implantação e fortalecimento de mecanismos e programas nacionais e internacionais de proteção e defesa da criança e do adolescente, em especial, aquelas em situação de vulnerabilidade ou de risco, como é o caso da criança ou adolescente vitimado pela exploração sexual, em cujos programas devem ser inseridas e engajadas as famílias das crianças e adolescentes vitimados, além de contar com a participação direta e ativa de toda sociedade civil (Art. 204, CF).

A exploração sexual da criança e do adolescente é um problema complexo e multicausal e, para erradicação desse problema que fere gravemente os direitos humanos dessas pessoas em desenvolvimento, não basta um sistema legislativo repressivo, deve-se buscar combater o efeito e não a causa; assim como não adianta a aplicação das medidas de proteção à criança e ao adolescente e a seus representantes (Art. 98 do ECA), elementar, a título de prevenção e erradicação, atentar às causas desse tipo de violência contra a criança e o adolescente, sendo certo que a causa reside, em grande parte dos casos, na pobreza, na desigualdade de classe social, de raça, de gênero e até mesmo regional.

O poder público e político, em toda a esfera de atuação, ou seja, nacional, estadual e municipal, deve estar comprometido na adoção de políticas públicas que visem à concretização e realização dos direitos humanos da criança e do adolescente, o que envolve não apenas metas e diretrizes que busquem resultados no presente e no futuro, como também a elaboração de projetos orçamentários que priorizem recursos necessários para efetivação dos direitos da criança e do adolescente, além de controle e fiscalização eficientes, tanto por parte do poder público quanto por parte da sociedade.

A Convenção sobre os Direitos da Criança impõe aos Estados-partes, portanto, ao Brasil, a adoção de medidas públicas, que envolvem medidas legislativas, orçamentárias, administrativas e de qualquer natureza no sentido de implementação e efetivação dos direitos da criança e do adolescente, ao conduzi-los ao pleno desenvolvimento das capacidades física, mental, social, moral e espiritual, na mais absoluta condição de liberdade e de dignidade. Nesse sentido, está disposto no Art. 19, 2, da CDC:

Essas medidas de proteção deveriam incluir, conforme apropriado, procedimentos eficazes para a elaboração de programas sociais capazes de proporcionar uma assistência adequada à criança e às pessoas encarregadas 
de seu cuidado, bem como para outras formas de prevenção, para a identificação, notificação, transferência a uma instituição, investigação, tratamento e acompanhamento posterior dos casos acima mencionados a maus-tratos à criança e, conforme o caso, para a intervenção judiciária.

Deve-se enfatizar a importância de se intensificar no âmbito nacional e internacional os esforços, a ação política e pública para a promoção, garantia e defesa dos direitos e garantias fundamentais da criança, ao priorizar o combate, a prevenção e erradicação dessa modalidade de violência que é a exploração sexual da criança e do adolescente.

Nesse aspecto, para a concretização da proteção integral da criança e do adolescente, urge o comprometimento do poder público (executivo, legislativo e judiciário) e o estabelecimento de um sistema de proteção integral por parte do Estado, da família e da sociedade, cuja tutela integral deve ser considerada sob três dimensões: promoção, controle e garantia. ${ }^{13}$

Atendendo às diretrizes das Nações Unidas, o Brasil criou o Conselho Nacional dos Direitos da Criança e do Adolescente (CONANDA) e o Conselho Estadual dos Direitos da Criança e do Adolescente (CONDECA), cujos órgãos, respectivamente, no âmbito federal e estadual, têm função deliberativa e controladora em matéria de atendimento aos direitos da criança e do adolescente; entretanto, em matéria de efetivação ou concretização da proteção integral com a prevenção e erradicação da exploração sexual, elementar o envolvimento de todos os segmentos da sociedade e um trabalho coordenado e intenso de todos os setores da sociedade no âmbito nacional, estadual e municipal.

$\mathrm{Na}$ verdade, o Estado é responsável pela política pública de garantia e preservação da dignidade e personalidade da criança e do adolescente; no entanto, não menos responsável é a sociedade, nela compreendidos empresas, igrejas, associações, ongs, poderes do Estado etc., pela adoção de políticas ou ações privadas de prevenção e erradicação da exploração sexual, pois, no Estado Democrático de Direito, toda a sociedade civil deve assumir a sua cota de responsabilidade para que se garanta o desenvolvimento sadio e harmonioso da criança e do adolescente, a quem pertence o futuro da nação.

A prevenção de todo tipo de violência, em especial, a que envolve a exploração sexual de criança e

$13 \mathrm{Id}$. adolescente requer um trabalho educativo, de conscientização, inclusão, e com a formação calcada em valores éticos e de consideração e respeito ao próximo, com envolvimento da família do menor vitimado.

Para erradicação da exploração sexual da criança e do adolescente, elementar, portanto, a adoção de metas e mecanismos através das políticas públicas, por exemplo, a ação pública manifestada através do "Plano Nacional de Enfrentamento da Violência Sexual Juvenil", que tem como propósito conhecer e conscientizar sobre o problema da violência sexual infanto-juvenil; fortalecer articulações e comprometer a sociedade civil para o enfrentamento; rever a legislação sobre o assunto e combater a impunidade; garantir atendimento prioritário às vítimas e estabelecer ações preventivas com a participação ativa de crianças e adolescentes pela defesa de seus direitos.

Entretanto, para o resultado efetivo dessas ações e políticas públicas, é elementar, além da articulação entre todos os segmentos da sociedade, a previsão orçamentária e destinação de recursos econômicos para campanhas educativas e de conscientização, além de acompanhamento individualizado e familiar por equipe interdisciplinar; destinação de curso profissionalizante ao menor e membros da família; bem como, criação de mecanismos de apoio e estímulo às denúncias contra exploração sexual.

O Brasil foi advertido, por intermédio de recomendação da ONU (Recomendação da ONU sobre Criança e Adolescente de 1\%/10/2007), que para garantia da proteção integral à criança e ao adolescente não adianta aumentar os investimentos federais na área da infância e juventude, mas sim a qualificação desse investimento, ou seja, uma distribuição justa e que atenda às camadas mais pobres e vulneráveis, considerando a latente e onipresente desigualdade de raça e regional existente no Brasil, o que pode comprometer a concretização da proteção integral.

Todas as ações e políticas públicas que envolvem proteção à criança e ao adolescente devem abranger todos os segmentos da sociedade e também deve haver um monitoramento, acompanhamento, fiscalização e avaliação por parte de órgãos como CONANDA, integrantes de ONGs, da sociedade e daqueles para quem são destinadas as políticas públicas e os recursos, que são as crianças e adolescentes, as quais devem participar da adoção de medidas de proteção e de destinação de recursos públicos, permitindo-lhes ocupar espaço de cidadania. 
É peculiar do Estado Democrático o pleno exercício da cidadania, a qual se consolida através da participação nas decisões políticas que dizem respeito à atuação estatal em todas as suas esferas, municipal, estadual e federal; inclusive no que tange ao poder de fiscalizar a administração pública. Sem cidadania, não há democracia e, sem democracia, não há cidadania. ${ }^{14}$ Portanto, a participação da sociedade, inclusive da criança e do adolescente nas políticas públicas voltadas para concretização da proteção integral, é a garantia de exercício da cidadania, a qual constitui um dos fundamentos da República Federativa do Brasil e do Estado Democrático de Direito.

Quanto à criança e ao adolescente vitimados pela exploração sexual, elementar uma política assistencialista e de atendimento voltada para proteção integral, portanto, que promova a sua recuperação e reinserção familiar e social através de uma educação especial e qualificada, serviços de saúde e atendimento psicológico adequado, cujo atendimento deve ser contínuo e extensivo à família da vítima, pois a proteção implica a manutenção da criança no seio da família, locus privilegiado para o pleno e integral desenvolvimento da criança e do adolescente.

\section{CoNCLUSÃo}

A ordem jurídica nacional e internacional reconhece a criança e o adolescente como sujeitos de direitos, bem como a condição de seres humanos em peculiar condição de desenvolvimento físico, psíquicos, social, moral, intelectual e espiritual, razão pela qual impõe à família, ao Estado e à sociedade a destinação de proteção integral e cuidado especial que os coloquem a salvo de forma de lesão a direitos humanos, inclusive, da exploração sexual.

A exploração sexual da criança e do adolescente é uma grave violação a direitos humanos dessa camada populacional, fere a liberdade, a personalidade, a saúde física e psíquica desses seres em desenvolvimento, atinge a dignidade humana comprometendo o desenvolvimento sadio e equilibrado da criança e do adolescente vitimados pela violência e exploração sexual, o que os torna, muitas vezes, adultos excluídos ou com sérios transtornos de personalidade e de convívio social.

Deve-se ponderar que os documentos internos e internacionais que revelam uma efetiva preocupação com a proteção integral da criança e do adolescente,

14 Ver Paulo Hamilton Siquiera Júnior \& Miguel Augusto Machado de Oliveira. Direitos Humanos e Cidadania. Revista dos Tribunais. 2009. embora sejam a mais pura expressão de reconhecimento e proteção aos direitos humanos especiais das crianças e dos adolescentes, não representam o bastante para a concretização da proteção integral; portanto, é elementar uma ação coordenada entre o Estado Nacional, Órgãos e Organismos internacionais, bem como de toda a sociedade civil através das escolas, igrejas, Ongs, empresários, entidades de classe, poderes do Estado (judiciário, legislativo e executivo) no sentido de mobilizar ações concretas de defesa e proteção concreta aos direitos da criança e do adolescente.

Incumbe ao Estado a implementação de políticas públicas que visem prevenir e erradicar a exploração sexual contra criança e adolescente, e que estabeleçam planos e ações de educação profissionalizante e de formação ética e cultural, com o objetivo de coibir e prevenir, através da conscientização, a prática sexual que envolve criança e adolescente, como forma degradante de trabalho ou para qualquer outra finalidade.

Em matéria de criança e adolescente, a política assistencialista deve ser destinada com prioridade absoluta e visar ao melhor interesse da criança e do adolescente, razão pela qual o Estado deve manter dotação orçamentária suficiente que objetive a destinação de recursos para manutenção de condições mínimas e dignas de vida. Enfim, é elementar, além do apoio educacional, psicológico e social, o apoio econômico à criança e ao adolescente e à sua família.

Justifica-se a proteção extensiva à família, pois a criança e adolescente, na maioria das vezes, é fruto do ambiente em que vive, e é certo que não adianta proteger e cuidar da criança isolando-a do locus de convivência; é importante, também, visando à proteção integral, cuidar do meio em que ela vive, logo, o que envolve o cuidar da família da criança e do adolescente.

\section{REFERÊNCIAS}

Celso Lafer. A reconstrução dos direitos humanos: um diálogo com o pensamento de Hannah Arendt. P. 124. Companhia das Letras. (1988).

Convenção sobre Direitos da Criança. Art. 1

Fábio Konder Comparato. A afirmação histórica dos direitos humanos. P. 33. Saraiva. (2010).

Grasiele Augusta Ferreira Nascimento \& Maria Aparecida Alkimin. Exploração sexual: uma das piores formas de trabalho infantil. Anais do Xx Congresso Nacional do CONPEDI/UfES. 2011. At. 2455. 
Guilherme Guimarães Feliciano. Violência sexual contra a criança e o adolescente no marco da precarização das relações de trabalho. Anais do I SEMIDI e I seviles. Centro Universitário Salesiano de São Paulo. 2010.

Norberto Bobbio. A era dos Direitos. Tradução de Carlos Nelson Coutinho. P. 34. Elsevier. (2004).

Paulo Hamilton Siquiera Júnior \& Miguel Augusto Machado de Oliveira. Direitos Humanos e Cidadania. Revista dos Tribunais. 2009.
Tânia da Silva Pereira. Direito da criança e do adolescente uma proposta interdisciplinar. P. 24. Renovar. (2008).

Tatiana Amaral Silva \& Marco Aurélio Ávila. Turismo sexual e exploração sexual infantil: uma análise da atuação do programa sentinela em Ilhéus. Revista de Turismo e Patrimônio Cultural. Disponível em: 06/10/2011. 